\title{
Can Artificial Intelligence Author Laws: A Perspective from Russia
}

\author{
Roman Dremliuga $^{1} \&$ Alexey Koshel $^{1}$ \\ ${ }^{1}$ School of Law, Far Eastern Federal University, Vladivostok, Russia \\ Correspondence: Roman Dremliuga, School of Law, Far Eastern Federal University, Vladivostok, Russia. Tel: 7- \\ 914-707-1474. E-mail: dreamluck@yandex.ru
}

$\begin{aligned} & \text { Received: June 21,2020 Accepted: July 17, } 2020 \\ & \text { doi:10.5539/jpl.v13n3p286 }\end{aligned}$
URL: https://doi.org/10.5539/jpl.v13n3p286

The study was carried out with the financial support of the Russian Foundation for Basic Research in the framework of research project No. 18-29-16129.

\begin{abstract}
This article discusses the issue of the introduction of digital technologies into policy-making. The article describes several systems of policy-making in the Russian Federation. In addition, the article discusses the issue of the introduction of a new System of policy-making in the light of the digital transformation of the Russian economy.

The paper analyzes the capacities of digital technologies, including artificial intelligence (AI), in the context of their application in policy-making. The authors conclude that there are prerequisites and opportunities for deeper automation of the policy-making. This can improve the quality of the bills, can increase public involvement in the policy-making process, and speed up the development and adoption of new regulations. An intelligent system can develop legislative bills that are of superior technical quality and are non-contradictory in the context of both national and international legal systems. Digitalization processes should naturally lead to changes in the mechanism of policy-making, which in turn should lead to its greater automation. Moreover, insufficient automation today can become an obstacle in the digital transformation of the Russian economy.

The authors conclude that in the future it would be possible for intellectual systems to author bills. The general development of AI systems shows that given the parameters of the problem and given the circumstance when the machine would be able to detect a center of social tensions in the community, the intelligent system itself would be capable of making proposals in the field of legislative regulation.

The application of intelligent systems in policy-making is not without its drawbacks. Such systems are not transparent in the legal and technical sense and can also transfer human beliefs into the texts of the regulations. These problems can be addressed through public scrutiny and the introduction of a licensing system, however even this would create a number of new practical challenges.
\end{abstract}

\section{Introduction}

Russia is now set off on the road for the digitalization. An important step in this direction was the adoption of the Federal Program on Digital economy of the Russian Federation. As was noted in the text of the Program, "digital economy is an economic activity where the key factor of production is data in the digital form, which contributes to the formation of an information space that takes into account the needs of citizens and society in obtaining reliable information of high quality." (Decree of the Government, 2017).

Digitalization is a term that came from countries that were the first ones to transform their economy and public administration in accordance with the latest trends in the field of information technologies. There are different definitions of digitalization, which vary depending on the context of their use. For example, The Informal Company Law Expert Group (ICLEG), established by the European Commission, defines digitalization as "representation of communication in writing or sound by electronic means and the concept thus concerns electronic communication including the transmission of information and the storage of such communication electronically and electronic access and retrieval from such storage." 1 Obviously, this definition lists possible primary operations with information, without reflecting much on the legal and economic nature of the term

\footnotetext{
${ }^{1}$ Report on digitalization in company law. March 2016 (official report of ICLEG to EC) URL: https://ec.europa.eu/info/sites/info/files/iclegreport-on-digitalisation-24-march-2016_en.pdf (accessed: 16.12.2019).
} 


\section{digitalization.}

Most often, digitalization is discussed in the context of the Fourth Industrial Revolution. For example, Klaus Schwab who is the founder and a long-time executive chairman of the World Economic Forum in Davos in his bestseller book Shaping the Fourth Industrial Revolution speaks about the unprecedented penetration of digital technologies in all aspects of life with the speed, which is only increasing (Schwab, 2018). Schwab also highlights the importance of AI, saying that it is already rebuilding the digital economy and will soon change the economy of the material world (Schwab, 2018, 143).

Progress in technology is a driving force in the development of all spheres of human society. It would be absurd to assume that this progress will not affect the governmental and legal spheres. This process is often referred to as the digitalization of law.

\section{Digitalization of the Legal Procedures in Russia}

The rhetoric of the leading Russian politicians coincides with the willingness of the Russian legal community to develop a legal system that would be in line with the trends of digitalization. This is illustrated by the plenary reports of the Prime Minister of the Russian Federation Dmitry Medvedev and the Minister of Justice of the Russian Federation Alexander Konovalov at the Opening Session of the St. Petersburg International Legal Forum in 2017; both reports were fully devoted to the motion of the legal profession towards digitalization.

Digitalization in Russia is not limited to political rhetoric only. Technologies have penetrated all spheres of life of the Russian government. For example, by choosing the Mobile Voter Service through the Russian Portal of Government Services, citizens have the right to choose beforehand a polling station convenient for expressing their will and to register themselves with this polling station. In Russia, this service has already been used twice: for the first time on March 18, 2018, during the Presidential Elections, ${ }^{2}$ and on September 9, 2018, during a Single Voting Day when this service could also be used for elections of the members of the provincial parliaments. ${ }^{3}$ Such technologies allow constitutional protection of the right of citizens to participate in the governance and to remove barriers to the fulfillment of this right, which was elaborated by Knyazev and Aranovsky (Aranovsky, 2012). Used since 2003, the State Elections Automated System of the Russian Federation was established by the Presidential Decree and put into effect by a Federal Law (Decree of the President, 1994), now allows monitoring of the counting of votes and the voter turnout in real-time, which increases the transparency of scoring of the voting results.

Since 2005, e-justice mechanisms have also been introduced in Russia. Use of the Portal of Government Services and the Automated State Justice System allows users to complain to the court about the violation of their rights without leaving their homes only by using the Internet (Lebedev, 2006). Besides, the Justice System and the system of access to the materials of arbitration courts offer quick access to information about the parties to the litigation, the progress of the litigation, and the practice of judicial disputes. This increases the availability and openness of the judicial system and allows lawyers to quickly analyze the court practice.

Similar examples of the penetration of digital era developments into the legal sphere are seen in all parts of the world. In 2000, electronic document management with an application of an electronic signature was made legal in Austria. Since 2004, the State Unified Court System in the US has been implementing e-justice mechanisms. Since 2008, Italy has also introduced an electronic document management system to the country's arbitration courts along with the existing paper-based system. In the United Kingdom, there are very elaborate intentions to introduce online courts while in court proceedings in the United States, electronic online case files have been a standard in the Admiralty (Maritime) courts, Commercial Courts, and Industrial courts since 2009 (Protas, 2016). E-justice systems have proven to be successful in Finland, Belgium, Hungary, Austria, and Slovakia, which corresponds to the commitments of these countries to the Lisbon Strategy 2000, the Hague Programme of Judicial Cooperation (2004-2007), and the European Public Information Program 2010 (Talimonchik, 2009).

\section{Digitalization of the Policy-Making Process}

Enactment of laws is the basic function of the state and the titular function of the Parliament as an expression of the will of the people who act as the source of power (Vasileva, 2012; Comparative Constitutional Law, 1996; Chudakov, 2001; Shapoval, 2007). The laws exist to regulate social relations fully and fairly as they bind regulation with the current level of development of society, taking into account the need to comply with the principles of

\footnotetext{
${ }^{2}$ For more information, see the materials on the official website of the Central Election Commission of the Russian Federation (electronic resource) URL: www.cikrf.ru/reception/dlya-otdelnykh-kategoriy-izbirateley/golosovanie-po-mestu-nakhozhdeniya/ (in Russian) (accessed 06.11.2018).

3 See more materials on the Russian Portal of Government Services (electronic resource) URL: www.gosuslugi.ru/help/news/elections_september_2018 (in Russian) (accessed 06.11.2018).
} 
constitutionalism and natural law (Pokrovsky, 1917).

The use of information technologies in Russian policy-making has a well-established practice. The Automated Policy-Making Support System became operational in 2001 and is still being used today. This System was instituted by Order No. 2-75 of the Chief of Staff of the State Duma of the Federal Assembly of the Russian Federation of June 29, 2001 (Order of the Chief of Staff of the State Duma, 2001). Automated Policy-Making Support System contains texts of the draft laws, all modifications made along with the explanations, financial justifications, conclusions, official reviews, information about the progress of the bill, timing of scheduled hearings, and information about the voting structure of both chambers of the Russian Parliament, the State Duma and the Federation Council (Veselov, 2017). This system increases not only the efficiency of information exchange within the Central Office of the State Duma, but also between Committees and the State Duma parliament members, and between the other government agencies. It should be noted that the use of such a system contributes to the implementation of the principle of openness of the policy-making process since anyone can get full information about the bill at any stage of its movement and after its adoption.

According to some scholars, the Automated Policy-Making Support System significantly improves the quality of policy-making support. The main purpose of the System is to ensure speeding up the passage of bills at all stages of the policy-making procedure. At the same time, the information resources created in the State Duma are consolidated and brought together into an integrated complex in order to be used more effectively during the policy-making (Tarasov, 2010).

Despite the positive effect of using the Automated Policy-Making Support System in Russia, this system is not without its drawbacks. Some features that have been used in document management systems for a long time are still not integrated into the Automated Policy-Making Support System. For example, such systems are often used to provide remote access to policy-makers and other persons involved in the bill drafting process. Consideration, review, or approval of the drafts, in this case, may occur not only when the policy-makers are at the office, but also during their business trips (Shulika, 2017). Foreign experiences show that systems like the Russian Automated Policy-Making Support System are no longer an innovation, but a necessary present-day requirement of an effective policy-making.

Following the demands of progress, it was necessary either to improve the traditional system or to develop a brand new system that would meet the requirements of the contemporary trends of digitalization. Therefore, in accordance with the Order of the Chief of Staff of the State Duma of July 21, 2017 No. 2-96 On the Experimental Operation of the Single Automated Public Policy-Making System in the State Duma of the Federal Assembly of the Russian Federation, July 24, 2017, became the date of commencement of the trial operation of the Single Automated Public Policy-Making System, which was developed by the Special Communications and Information Service of the Federal Protective Service of the Russian Federation. ${ }^{4}$

According to the description, the functionality of a new system includes automated drafting of the documents; long-term, medium-term, and short-term planning; semantic processing of the minutes of the meetings and automatic registration of the decisions listed in the minutes; integrated policy reference subsystem; generation of templates of the documents in the system with the registration record details; prompt notification of the parties of the policy-making process about the draft changes; and automatic control of the published documents and their records details. The system has a flexible customized interface for viewing the drafts on any workstations and mobile devices along with a special application for mobile devices based on both iOS and Android platforms. ${ }^{5}$

A system with this kind of functionality can be called an intelligent system since semantic processing is no longer a purely technical operation. This type of information processing involves working with the meaning of texts and logical connections between them (Zuenko, 2010). This replacement of the Automated Policy-Making Support System that has existed for over a decade with the Single Automated Public Policy-Making System reflects a global trend where digital technologies are considered not only as a means of aggregation and transmission of information but also as a potential replacement of human intellectual labor. Working with meanings has always been inherent only to humans and was beyond automation, but recently there has been a clear trend to use AI systems to address this type of issues.

In addition, there are automated systems that focus at the earlier stage of enactment of laws - the stage of policy drafting. There are several systems of this kind in Russia today, including the Federal Portal of Policy Drafts ${ }^{6}$ and

\footnotetext{
${ }^{4}$ See: URL: https://asozd2.duma.gov.ru/ (accessed: 18.10.2018) (in Russian)

${ }^{5}$ See: URL: https://ppr.ru/projects/?id_4=8 (accessed: 03.04.2019) (in Russian)

${ }^{6}$ URL: http://regulation.gov.ru (accessed: 17.09.2019) (in Russian)
} 
the Automated Information System of Project Management titled Cloud-Based Solution for Automation of Government Project Management. ${ }^{7}$

The above-mentioned systems have unique features. From this perspective, while the Portal as its main function has disclose of information about the workings of the government agencies and ensuring a broad discussion of draft regulations, including the bills developed by the Russian government with the purpose of conducting a public anti-corruption assessment, the Automated Information System of Project Management, on the other hand, focuses at the intellectual support of project workings of the government, which is especially important given the transition of the Russian Federation to a state programs-based management mechanism, the so-called program budget, which is implemented through the Article 179 of the Budget Code of the Russian Federation. Unfortunately, the format of this publication does not allow us to provide a comprehensive analysis of these solutions, but it needs to be noted that these systems do not have a functionality to offer intellectual solutions to the policy-making initiatives, but only focus at automated intellectual support of the policy-making in application to the already drafted bills. ${ }^{8}$

Despite significant improvements in the systems that serve policy-making, policy-makers should still go even further. Active development of AI technologies makes it possible not only to generalize and to identify meanings but also to generate them.

Until recently, digital technologies have been used mainly to address routine technical tasks mostly in the field of science and technology. Humans on the other hand would keep the intellectual and creative functions along with the right to make decisions. With the development of AI, these purely human functions have also become accessible to computer systems.

AI can make financial and business decisions that are too complex even for humans (Baur, 2015). Computer systems that can make decisions independently without human interventions are now been installed in cars and other vehicles (Chen, 2017). Would it also make it possible for a robot to become a policy-maker? There are now reasons to say so.

At the moment, the government institutions have become a roadblock on the way of technological progress and digital transformation, and there are no mechanisms of a prompt regulation of issues associated with the protection of the rights and legitimate interests of citizens, legal entities, and transnational corporations in the context of the rapid development of the digital economy.

The Fourth Industrial Revolution has brought government institutions far more problems than solutions. In the era of the digital economy, the government machinery is becoming subject to increasing turbulence as all decisions now become scrutinized by the public, and any government action becomes almost impossible to hide from the public. The speed of technology development and the speed of the emergence of new mechanisms, devices, and applications require prompt regulation.

According to the libertarian legal theory, at the present stage, both the state and law are universal and necessary forms of normative existence, expression, recognition, and implementation of citizens' freedoms and liberties in their social lives (Nersesyants, 2003). However, the government no longer has the time for linear strictly regulated policy-making procedures, which require a long sequence of approvals between various government agencies and offices (Schwab, 2016).

As a solution, Klaus Schwab, executive chairman of the World Economic Forum in Davos, suggests the concept of flexible governance, that is, the creation of a legal ecosystem that provides a mobile response of the government to the changes in science and technology, which lead to the changes in the society. Such flexible governance, in Schwab's understanding, should be based on the following principles: (1) guarantees of human rights and freedoms; (2) priority of individual interests; (3) consensus between government, business, and civil society.

Therefore, by making the digital system not an assistant, but the basis of policy-making, policy-makers can achieve incredible results. This offers an opportunity to model the impact of the drafted policy on society (Olaya, 2010). AI systems allow users to automatically search for logical and legal contradictions in the context of the entire regulatory field, including the international legal space (Ashley, 2017). In addition, smart digital systems allow users to automatically detect the impact of policies on each other and to determine the repetitive use of the text and text structures in the national legislation (Burgess). In other words, from a technical perspective AI applications can already generate policy texts with a specified targeted meaning, which will be integrated into the existing legal system.

\footnotetext{
${ }^{7}$ URL: https://regulation.gov.ru/projects\#npa=78373 (accessed: 17.09.2019) (in Russian)

${ }^{8}$ URL: http://pravo.gov.ru (accessed: 17.09.2019) (in Russian)
} 
At a first glance, it may seem that such a policy will not be accepted by society, but international experiences demonstrate that technologies allow us to identify the attitude of certain social groups towards the policies and to encourage their direct involvement in the formulation of the policy text. For example, Iceland used such a mechanism to formulate the text of the Constitution. As Hudson suggests, "Careful study of this case can therefore inform our understanding of how public participation in lawmaking may be supported by new technology" (Hudson, 2018).

It turns out that an intelligent system can develop high-quality bills from the point of view of legal writing, which will be consistent with the national and international legal systems. In addition, a computer system can provide for interaction with the public and can take people's opinions into account.

In the future, the use of AI in the policy-making will become even more pronounced. Khabrieva in her works has repeatedly emphasized that digitalization will most likely lead to changes in the mechanism of policy formation and in the composition of the existing model of social regulation. Digital transformation can lead to the correction of the boundaries of known social regulators and to the formation of a niche, which will be occupied by the program code (Khabrieva, 2018). For example, in the case of a total transition to electronic payments, there would be no need for complex tax legislation: instead what would be needed is just an executable computer code that automatically deducts a certain percentage of money received by businesses (Dremliuga, 2018). In other words, the policy will be enforced by itself and there would be no need to adopt a law that will be enforced by law enforcement government agencies.

There are already international sources that help set standards for legal coding. An example of this is the European General Data Protection Regulation (GDPR), which imposes restrictions on automatic decision-making in the cases of making legally significant decisions. This means that the practice of automatic decision-making in the making of legally significant decisions is now officially sanctioned. According to the text, the person against whom the decision is made must be aware of the logic of how this decision was made. ${ }^{9}$ A similar principle is applied in the European Union when concluding automatic contracts based on blockchain (Hofman, 2019) and other technologies (Brkan, 2019). This practice should also be extended to automatic policy-making. The logic of decision-making algorithms for data processing and decision-making itself should be understandable by humans. The human right to explain the order of decision-making by the algorithm now even has its own name - the right to explanation (Bryce, 2016).

In the conditions of total digitalization, policy-making can be carried out not only by the government but also by the individuals and by the legal entities. Most often, these are entities that control information flows with a real technical ability to make an impact on these flows. For example, by applying software code Facebook automatically eliminates violations of children's rights, violations of intellectual property rights, publishing of posts that provoke ethnic-based hate, etc. ${ }^{10}$ In other words, Facebook as a company establishes a policy for publishing information and develops a system of rules while the algorithm in accordance with these rules decides if the material published by a Facebook user violates someone's rights (Gorwa, 2019). Only if the user does not agree with the decision made, does the government (regulatory authorities, courts) get involved in the resolution of the dispute.

Despite the fact that the adoption of such rules is not a policy-making in the classical sense, such rules make a direct impact on the public relations, since the user cannot physically fail to follow the rules established by the social network. This means that the private sector already has technologies for automated policy-making with minimal human intervention and automated enforcement of such policies. To what extent this experience is applicable for automating the policy-making process is a matter of further research.

Policy-making is not only a governance process per se as it still remains a creative function of human intelligence. It can be handed over to the execution by machines only if it is subsequently carried out through the means of direct or representative democracy, which must, in any case, ensure respect of the public interests. But the robot can be handed over a function to collect materials or in the future to compose the text of the explanatory notes to the drafted policy, which is now mandatory at the stage of consideration of the drafted policies in a number of countries.

For example, the rules of policy-making (Guide to Making Legislation), adopted in 2017 by the Cabinet of the United Kingdom, establish that such explanatory notes shall include: a description of the role of the bill, a brief

\footnotetext{
9 Articles 13(2)(f), 14(2)(g) and 15(1)(h), General Data Protection Regulation (GDPR), Regulation (EU) 2016/679, URL: https://ogdpr.eu/ru/gdpr-2016-679 (accessed: 18.01.2019).

${ }^{10}$ URL: https://gizmodo.com/here-s-everything-that-s-banned-on-facebook-all-on-one-1825495383 (accessed: 18.01.2019).
} 
overview of legislation in this area, an existing legal regulation, proposed changes and reasons for changes, a scope of legal regulation of the bill, persons and jurisdictions covered by the bill, characteristics of the bill and its parts, interpretation of special terms used in the bill, and examples of the bill's legal applications for the MPs who do not have special knowledge in this area of legal regulation. ${ }^{11}$

You can hand over the function to analyze the legal writing of the proposed bill to the robot already today as well. After all, given the fact that MPs are not subject to mandatory requirements of having or not having special knowledge in the policy-making field, a legal assessment of policy initiatives remains utterly desirable (Vasileva, 2016).

At the same time, a review of technical literature shows that there are significant restrictions on the application of AI systems in policy-making. The main issue associated with the application of algorithms is the lack of transparency, which raises doubts about the feasibility of applying AI systems in policy-making (Moses, 2016). According to the text of the Russian National Strategy for the Development of Artificial Intelligence 2030, transparency is one of the main principles of application of the AI technologies (The National Strategy for the Development of Artificial Intelligence 2030, 2019). The lack of transparency can be understood in two contexts: legal opacity (inability to access the program code due to its protection by the intellectual property rights and by the trade secrets) (Wexler, 2017) and algorithm opacity (difficulty in understanding of how the algorithm works) (Datta, 2016).

The opacity of understanding of algorithms and their applications also could be divided. Some authors divide the second form of opacity into the two types depending on the complexity of its understanding (Burrell, 2016). The first type stems from characteristics of observer of predictive policing systems, which implies that a person trying to understand such systems would need to have special knowledge and skills in the field of computer science. This type of opacity can be easily surmounted in specific isolated cases, but it is a big problem in general. This is the reason why there is a growing market demand for employment of people who understand algorithms and especially machine learning algorithms to address this problem (Au-Yong-Oliveira, 2019). The second type is 'objective' opacity, which stems from the limits of human skills in reasoning and semantic interpretation. Machine learning used in predictive policing could have multidimensional space of variables on both the input and the output levels that can be out of human capabilities.

International experiences demonstrate that being developed by private companies, these algorithms are protected by laws on the protection of intellectual property and by the trade secrets. In practice, this means that neither the legislative bodies purchasing the software nor the third parties have access to the source code and sometimes to the technical documentation of the product (Couchman, 2019). As a result, the algorithm operator such as the legislature does not have the ability to understand what processes occur during data processing and, consequently, how the algorithm makes particular decisions.

The consequence of opacity in the legal sense is the inability to exercise public scrutiny over the operation of the algorithm and over the work of the policy-makers who apply it. Given the current lack of transparency, it is difficult to guarantee the correct operation of the algorithm. Since the operator of the intelligent system does not have access to the source code, it makes it impossible either to prove or disprove the charges in incorrect operation of the algorithm.

Allowing everyone to access the source code and weights of the AI system also carries significant risks as this algorithm offers a competitive advantage to the government that applies it, and publication of the source code can deprive the government of this advantage. In addition, open-source code can allow hackers to find vulnerabilities in the system to alter its operations, which contradicts the security principle specified in the National Strategy for the Development of Artificial Intelligence 2030.

Having access to the source code and weights of the algorithm is not a guarantee that the mechanism for making policy decisions by AI would become more transparent. As some studies show, despite the high accuracy and reliability of the algorithms applied, their work often remains a black box for the users in terms of how these algorithms generate decisions or predictions based on the input data. Thus, one can say exactly how many times the algorithm would give a correct answer or make the right decision (often surpassing the human capacities), but it is technically very difficult to answer the question of how AI does that.

According to some scholars, "deciphering the black box has become exponentially harder and more urgent. The technology itself has exploded in complexity and application" (Castelvecchi, 2016). Day after a day, intelligent

11 URL: https:/www.gov.uk/government/uploads/system/uploads/attachment_data/file/450239/ Guide_to_Making_Legislation.pdf. pp. 77112 (accessed: 04.01.2019). 
systems and algorithms become more sophisticated and much more difficult to understand.

Some scholars claim that the issue of understanding of intelligent systems may become even more severe. Deep neural networks, which are the most popular type of AI, start to give completely wrong results when the input data is altered in a special way (Nguyen, 2015). This means that currently applied algorithms could easily be misled in a random or deliberate way, and it is difficult to predict in which cases that might happen.

No lesser severe is the issue of inheritance of human biases by the algorithms. Often, AI systems are trained on data created by humans. The models that algorithms can generalize from this data are sometimes contradictory from an ethical and a legal perspective. By learning from arrays of data created by humans, algorithms can inherit our misconceptions. Government agencies should not discriminate against any social group, however, algorithms may still inherit human biases, which can be reflected in policy-making.

The issues of AI application in policy-making can be eliminated by increasing the role of public scrutiny over the application of such systems. It is necessary to establish clearly defined standards for certification of policy-making systems. Such systems should only function if they have proven to be effective and if they do not violate human rights, including violations caused by biases. For this purpose, special certification panels can be established along with clearly identified assessment standards that should be applied to prediction systems. Besides, it is obvious that certification should be applied, if necessary, not only to private sector solutions but also to the solutions developed by the government agencies themselves.

Certification (licensing) systems are already used to examine intelligent systems. For example, in Nevada manufacturers must prove that their cars are safe in different weather conditions, on different types of terrain, and at different times of the day (Vellinga, 2016). Similar to the logic of certification (licensing) of self-driving vehicles, it might be necessary to require developers to provide evidence that such policy-making systems have been tested in various conditions to prove their predictability and respect for fundamental human rights and freedoms.

Some scholars note that creating a visualization system that shows how the algorithm functions is a non-trivial engineering task that requires time and effort (Buiten, 2019). Thus, the decision to make the developer visualize the operation of the algorithm used in policy-making should be accompanied by an economic assessment of the consequences of doing so for the developer.

\section{Conclusion}

In the summary, one should note that Russia has done a large-scale work to digitalize its policy-making process since the Single Automated Public Policy-Making System meets the requirements of the contemporary trends and is in some sense an intelligent system. The question of transferring the full scope of policy-making to intelligent systems is still premature. However, international experiences and recent achievements in the development of AI systems demonstrate that the introduction of intelligent systems to improve the quality of the policy texts is advisable. Application of advanced technologies for further improvement of the Single Automated Public PolicyMaking System, the Automated Information System of Project Management, and the regulation.gov.ru portal, first of all, should focus at the improvement of the policy-making by application of the mechanisms of intelligent machine analysis of big data, by identifying internal contradictions and gaps in the regulation, and by eliminating the duplicative policies. In addition, international experiences also show that state-of-the-art technologies can ensure greater public involvement in policy-making.

It can be argued that today machine data processing technologies are already being applied in the drafting of explanatory notes and in the assessment of the bills' financial and economic justification. The application of machine data processing models is one of the most promising opportunities in the development of policy-making. Given the complexity of machine learning in the field of regulation, it can also be argued that while machines are now fully capable of doing data search and analysis along with the necessary calculations, today they can only do that on the basis of human-proposed algorithms and behavior models. In the future, if humans develop a sufficient number of standard protocols and models for data collection and analysis, depending on the specified parameters, the machine itself will be able to create a protocol and a model for data collection and analysis to follow them through and to offer solutions. Therefore, the objective here is to train AI by creating as many models as possible.

Taking into account the fact that legal writing is also subject to strict rules of formal logic, in the future, it would be possible to describe the algorithm of the policy drafting itself. General development of AI systems shows that given the parameters of the issue or given the fact that the machine can detect a hotbed of tensions in the society by analyzing social media, AI itself would be capable of forming proposals in the field of policy regulation. However, analysis demonstrates that the application of the AI systems in policy-making is not without its drawbacks. Such systems are not transparent in the legal and technical sense and may also transfer certain human 
biases to the policy texts. These problems can be addressed through the public scrutiny and the introduction of a licensing system, however even this would create a number of new practical challenges.

\section{References}

Aranovsky, K. V., \& Knyazev, S. D. (2012). Once again about the active electoral right of Russian citizens who do not have registration at their place of residence. Comparative Constitutional Review, 5, 155-164.

Ashley, K.D. (2017) Artificial Intelligence and Legal Analytics. Cambridge University Press. https://doi.org/10.1017/9781316761380

Au-Yong-Oliveira, M. C. (2019). The role of AI and automation on the future of jobs and the opportunity to change society. Advances in Intelligent Systems and Computing, 932, 348-357. https://doi.org/10.1007/978-3-03016187-3_34

Baur, A. W., Bühler, J., \& Bick, M. (2015). How pricing of business intelligence and analytics SaaS applications can catch up with their technology. Journal of Systems and Information Technology, 17(3), 229-246. https://doi.org/10.1108/JSIT-03-2015-0024

Brkan, M. (2019). Do algorithms rule the world? Algorithmic decision-making and data protection in the framework of the GDPR and beyond. International Journal of Law and Information Technology, 27(2), 91121. https://doi.org/10.1093/ijlit/eay017

Bryce, G., \& Seth, F. (2016). European Union regulations on algorithmic decision-making and a right to explanation. ICML Workshop on Human Interpretability in Machine Learning. Retrieved from https://arxiv.org/pdf/1606.08813v3.pdf

Buiten, M. (2019). Towards Intelligent Regulation of Artificial Intelligence. European Journal of Risk Regulation, 10(1). https://doi.org/10.1017/err.2019.8

Burgess, M., Giraudy, E., \& Katz-Samuels, J. (2016). The Legislative Influence Detector: Finding Text Reuse in State Legislation. KDD'16 Proceedings of the 22nd ACM SIGKDD International Conference on Knowledge Discovery and Data Mining. San Francisco, 57-66. https://doi.org/10.1145/2939672.2939697

Burrell, J. (2016, January-June). How the machine 'thinks': Understanding. Big Data \& Society, 1-2.

Castelvecchi, D. (2016). Can we open the black box of AI? Nature. https://doi.org/10.1038/538020a

Chen, X.-M., Tian, G., Miao, Y.-S., \& Gong, J.-W. (2017). Driving Rule Acquisition and Decision Algorithm to unmanned Vehicle in Urban Traffic. Beijing Ligong Daxue Xuebao/Transaction of Beijing Institute of Technology, 37(5). 491-496.

Chudakov, M. F. (2001). Constitutional Law of Foreign Countries: Textbook. Minsk.

Comparative Constitutional Law: textbook. (1996). Ed. Chirkin V. E. Moscow.

Couchman, H., \& Prezepiorski, A. (2019). Policing by Machine. Predictive Policing - the threat to our Rights. L.IBERTY. Retrieved from https://www.libertyhumanrights.org.uk/sites/default/files/LIB\%2011\%20Predictive\%20Policing\%20Report \%20WEB.pdf

Datta, A., Sen, S., \& Zick, Y. (2016). Algorithmic transparency via quantitative input influence: Theory and experiments, with learning systems. 2016 IEEE symposium on security and privacy, 598-617. https://doi.org/10.1109/SP.2016.42

Decree of the Government. (2017). of the Russian Federation of 28.07.2017 No. 1632-R On Approval of the Program on Digital Economy of the Russian Federation. Collection of Legislation of the Russian Federation, 2017. No. 32. Article 5138.

Decree of the President. (1994). of the Russian Federation of August 23, 1994, No. 1723 On the Development and Establishment of the State Elections Automated System of the Russian Federation.

Dremliuga, R. I., \& Koshel, A. S. (2018). Artificial Intelligence as a Social Regulator: Pros and Cons. Asia-Pacific Region: Economy, Politics, and Law, 3, 55-68. https://doi.org/10.24866/1813-3274/2018-3/55-68

Gorwa, R. (2019). What is platform governance? Information Communication and Society, 22(6), 854-871. https://doi.org/10.1080/1369118X.2019.1573914

Hofman, D., Lemieux, V. L., Joo, A., \& Batista, D. A. (2019). The margin between the edge of the world and infinite possibility: Blockchain, GDPR and information governance. Records Management Journal, 29(1-2), 240-257. https://doi.org/10.1108/RMJ-12-2018-0045

Hudson, A. (2018). When Does Public Participation Make a Difference? Evidence from Iceland's Crowdsourced Constitution. Policy Studies Organization, 10(2). https://doi.org/10.1002/poi3.167 
Khabrieva, T. Y. (2018). Law Confronted by the Challenges of Digital Reality. Journal of the Russian Law, 9, 516. https://doi.org/10.12737/art_2018_9_1

Lebedev, V. M. (2006). Computerization and Informatization of courts as an imperative of our time. Informatization of courts, 29.

Maslov, A. O. (2016). On the role of the explanatory note in the policy-making process. Contemporary Problems of the Russian Law, 10(71), 38-47.

Moses, L. B., \& Chan, J. (2016). Algorithmic prediction in policing: assumptions, evaluation, and accountability. Policing and Society, 12-13.

Nersesyants, V. S. (2003). Jurisprudence. Introduction to the General Theory of Law and State. Legal Thought: an Anthology. Yekaterinburg: Business Book. 1002-1009.

Nguyen, A., Yosinski, J., \& Clune, J. (2015). Deep neural networks are easily fooled: high confidence predictions for unrecognizable images. Proceedings of the IEEE Computer Society Conference on Computer Vision and Pattern Recognition, 427-436. https://doi.org/10.1109/CVPR.2015.7298640

Olaya, C. (2010). Model-based lawmaking and the curious case of the Colombian criminal justice system. Kybernetes, 39(9/10). https://doi.org/10.1108/03684921011081231

Order of the Chief of Staff of the State Duma. (2001). of the Federal Assembly of the Russian Federation No. 275 of June 29.

Pokrovsky, I. A. (1917). The main problems of civil law. PTG: Right.

Protas, D. V., \& Protas, E. V. (2016). E-justice as an innovative global trend. Proceedings of the International Research and Practice Conference on the Management in the Field of Research, Training and Technological Development. Moscow: Moscow Polytechnic University, 551-555.

Schwab, K. (2018). Shaping the Fourth Industrial Revolution. Moscow: Eksmo Publishing House.

Shapoval, V. N. (2007). Comparative Constitutional Law. Kiev.

Shulika, V. V. (2017). On the Issue of Remote Application of Automated Systems of Policy-Making. Knowledge Economy: Innovative Ecosystem and the New Industrialization of the Region. Materials of the Russian National Innovation Youth Forum. Moscow, 93-99.

Talimonchik, V. P. (2009). International Experiences of Application of Information Systems in Courts. Information Law, 1(16), 14-17.

Tarasov, A. M. (2010). Information technology in the parliamentary activities. Bulletin of the Academy of Law and Management, 21, 9-35.

The National Strategy. (2019). for the Development of Artificial Intelligence 2030 was adopted by a Decree of the President of the Russian Federation No. 490 of October 10, 2019 On the Development of Artificial Intelligence in the Russian Federation.

Vasileva, T. A. (2012). Legislative Powers of Parliaments in European Countries: Current Trends. Proceedings of the Institute of State and Law of the Russian Academy of Sciences, 1, 138-156.

Vasileva, T. A. (2015). How to Draft a Law. Moscow: Uright Publishing House.

Vellinga, N. E. (2016). From the testing to the deployment of self-driving cars: Legal challenges to policymakers on the road ahead. Computer Law and Security Review, 33(6), 847-863. https://doi.org/10.1016/j.clsr.2017.05.006

Veselov, I. G., \& Komarov, S. A. (2017). Technologies of the legal monitoring in the policy-making process of the State Duma of the Federal Assembly of the Russian Federation. Bulletin of the Nekrasov Kostroma State University, 22(1), 228-233.

Wexler, R. (2017). Life, Liberty, and Trade Secrets: Intellectual Property in the Criminal Justice System. Standford Law Review, 1-87. https://doi.org/10.2139/ssrn.2920883

Zuenko, A. A., \& Friedman, A.Y. (2010). Semantic Processing of Information in the Contemporary Factographic Systems. Proceedings of the Kola Scientific Center of the Russian Academy of Sciences, 3(3), 23-28.

\section{Copyrights}

Copyright for this article is retained by the author(s), with first publication rights granted to the journal.

This is an open-access article distributed under the terms and conditions of the Creative Commons Attribution license (http://creativecommons.org/licenses/by/4.0/). 